\title{
Rebar Truss Stiffened Concrete Composite Beams with U-Shaped Steel Girders under Bending Moments
}

\author{
Ran He*, ZhangQi Hu and ZaiHua Zhang \\ College of Civil Engineering, Hunan City University, Yiyang 413000, China \\ Received 12 May 2020; Accepted 27 July 2020
}

\begin{abstract}
Encased U-shaped steel concrete composite beam is a newly developed composite beam with extensive use. The section of the U-shaped beam is not closed and thus has limited constraints to internal concrete. The reinforced cast-in-place concrete slab in the upper part is not suitable for fabricated structures. To improve the adaptability of the U-shaped steel concrete composite beam in the fabricated structure, concrete composite beams stiffened by fabricated rebar truss with Ushaped steel girders was proposed. First, static loading tests were performed for the two proposed composed beams. Second, failure mode, force-displacement curve, depth of the compression zone, strain distribution, and the global performance of steel and concrete under positive and negative bending moments were compared and analyzed. Results demonstrate that the specimen under positive bending exhibits ductile failure mode and has strong deformation capacity with its ductility coefficient of up to 5.34, indicating that the proposed composite beam is simple and reasonable and has strong integrity. However, the specimen under negative bending is buckling. This study provides references for the popularization and application of the novel composite beam to the fabricated structural industry.
\end{abstract}

Keywords: fabricated composite beam, U-shaped steel girder, bending moment, failure mode, rebar truss, global performance

\section{Introduction}

As structural engineering develops, the structure of single material can barely meet the comprehensive requirements of mechanical properties, durability, economic efficiency, applicability, and construction performance [1-3]. Different materials of composite structure have complementary advantages. However, the rational use of materials is the key to structural performance [4]. Newly developed encased Ushaped steel concrete composite beam is poured in U-shaped steel to form the ribs, and the reinforced concrete flange is casted in situ. The U-shaped steel and concrete collaborate with each other under the action of the interface bond stress and shear connectors. In addition to the advantages of traditional steel and concrete composite beams, The encased U-shaped steel concrete composite beam also has the following advantages [5-9]: (1) concrete filled in rib has supporting effect on the lateral plate of U-shaped steel, which prevents local buckling and overall instability; (2) Ushaped steel and concrete form a composite section, which can improve the shear bearing capacity and avoid brittle shear failure [10-11]; (3) U-shaped steel has a restraining effect on rib concrete, which enhances the stiffness and bearing capacity under negative bending moment; (4) Ushaped steel plate can be used as the construction formwork of a concrete beam, which can reduce working procedure, shorten construction period, and save project cost; and (5) concrete filled in U-shaped steel can absorb heat, slow down the heating rate of steel components, and improve the overall fire resistance of composite beams. Therefore, U-shaped steel concrete composite beams have broad engineering

*E-mail address: heran01033101@163.com

ISSN: 1791-2377 @ 2020 School of Science, IHU. All rights reserved. doi:10.25103/jestr.134.19 application prospects.

Everted [12] and introverted [5] U-shaped steel beams are commonly used at the lower part of composite beams. These forms of U-shaped steel beams have open sections, which have limited restraining effect on internal concrete. The failure of U-shaped steel beams and inner concrete can lead to slippage or drum bending. Therefore, the section of U-shaped steel beams must be improved. The cast-in-place reinforced concrete structure is generally used in concrete slab above the composite beam, which requires on-site formwork and is not suitable for fabricated structures.

On the basis of the existing U-shaped steel concrete composite beams, this study developed concrete composite beams stiffened by fabricated rebar truss with U-shaped steel girders and analyzed their mechanical properties, failure mode, and bearing capacity.

\section{State of the Art}

At present, scholars have studied on U-shaped steel concrete composite beams. Bradford [13] studied the slip effects between U-shaped steel and concrete and the flexural properties and local buckling properties of the steel plate of cold-bended thin-walled U-shaped steel concrete composite beams. The experimental results showed that the internal concrete of U-shaped steel could effectively improve the flexural properties, which enhanced the overall stability and bearing capacity of the composite beams. A thin-walled steel concrete composite beam with "pre-embedded" and "selftapping" shear connection modes was proposed, and a thinwalled steel and concrete test was designed to study the shear connection performance of the two shear connection modes. However, the self-tapping shear connection was only suitable for thin steel plates with a thickness below $2 \mathrm{~mm}$ 
[14]. Then, a removable assembled composite beam was introduced [15]. The lower part of the beam was an I-shaped steel beam, and the upper part was a profiled steel plate concrete panel, which were directly connected through the embedded bolts. Such a composite beam was suitable for fabricated structures; but its lower part was an I-shaped steel beam. A static test was conducted to study U-shaped steel concrete composite beams [16, 17]. Their results had been successfully applied in practical projects. However, the shear connector of encased U-shaped steel reinforced concrete composite beams was studs, which had the disadvantages of complex structure, large amount of stud welding, and poor construction quality. High-strength everted U-shaped encased steel concrete composite beams was studied, illustrating that high-strength concrete and high-strength everted U-shaped encased steel were connected by shear studs [18]. Moreover, the shear stirrup added to the concrete in the U-shaped beam could enhance integrity. Nevertheless, the section of the everted U-shaped steel was not closed. A novel U-shaped steel encased concrete composite beam was designed [19], and its shear connectors were free welding steel plate. The authors tested the bending properties of continuous beams. A finite element analysis of composite beams was performed [20], revealing that the flexural bearing capacity of the normal section of the beam could be calculated through simplified plastic theory. However, the upper-panel rebar needed to pass through the U-shaped beam steel plate, and the structure was complex. Keo et al [21] and Liu et al. [12] proposed to weld an angle steel as the shear connector on the everted steel flange of a U-shaped encased steel. Their results verified that the connector had good performance, but a large amount of angle steel was used. Zhou et al. [5] and Liu et al. [22, 23] welded a continuous Z-shaped reinforcing bar on an inverted Ushaped encased flange to form a closed section. A U-shaped stirrup was used as a shear connector. The test results showed that the composite beam had good global performance. In the test, slip or drum bending occurred at the lower part of the U-shaped steel beam and the inner concrete, indicating that the restraining effect and the integrity of the lower U-shaped steel on the concrete should be further improved. Zhao [24] studied the torsion resistance of a concrete truss composite beam reinforced by inverted U-shaped steel; however, the truss was a plane truss, and only the U-shaped steel beam was connected. Kim [25] developed a novel U-shaped steel concrete composite beam and tested its flexural behavior. The composite beam Ushaped steel was fixed on a C-shaped thin-wall steel plate by two Z-shaped thin-wall steel bolts. The bolt was likely to slip in the loading process. The upper panel of the composite beam was a common cast plate, which was unsuitable for fabricated structures. On the basis of the above literature, the proposed novel concrete composite beam stiffened by fabricated rebar truss with U-shaped steel girders had not been reported.

Kemp [26] and Tong [27] found that traditional steel concrete composite beams had poor stability under negative bending moment. Controlling the height-to-thickness ratio of the web was necessary to increase the bearing and rotation capacities of the composite beams. Yang et al. [28] indicated that filling concrete in a negative moment area could form a constraint on the web concave. However, convex buckling was inevitable. On the basis of the literature, study of the mechanical behavior of U-shaped steel composite beams under negative bending moment was scarce.

Given that few studies have focused on the new assembled composite beams, the bending performance of two simply supported beam specimens was tested in this study to verify its rationality and investigate the effects of positive and negative bending moments on the mechanical properties. The failure mode, load deflection curve, compression zone height, strain distribution rule, and the global performance of U-shaped steel and upper concrete slab under the positive and negative bending moments were compared and analyzed, which provided reference for the engineering application of the novel concrete composite beams stiffened by fabricated rebar truss with U-shaped steel girders.

The remainder of this study is organized as follows. Chapter 3 introduces the experiment. Chapter 4 compares and analyzes the test results of failure mode, load-deflection curve, and strain distribution rule. Chapter 5 summarizes this study and draws the conclusions.

\section{Methodology}

\subsection{Design and structure of the specimen}

The lower part of concrete composite beams stiffened by fabricated rebar truss is a cold-bended thin-walled box girder, the upper part of which has a long elliptical hole. The upper part is a reinforced rebar truss deck, and no additional floor formwork is needed (Figure 1). The two components can be manufactured in a factory. At the construction site, the space rebar truss can be directly welded to the upper part of the Ushaped steel beam, and then the concrete will be uniformly poured to the assembly components. The spatially reinforced truss acts as a shear connector. The key problem of the composite beam is the shear connector between the lower Ushaped steel beam and the upper concrete, which can ensure their joint operation.

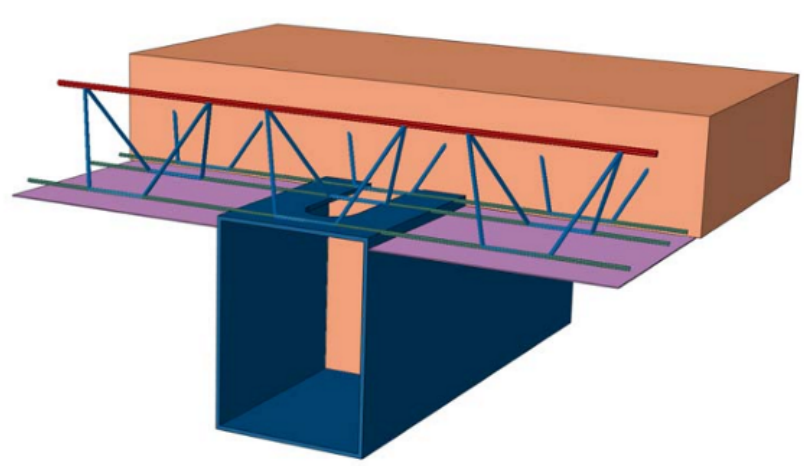

Fig. 1. Structure of concrete composite beams stiffened by fabricated rebar truss with U-shaped steel girders

Fig. 2 shows the structure of the composite beam specimen. The composite beam specimen is a T-shaped simply supported beam. The bottom width of the T-shaped beam is $b=150 \mathrm{~mm}$, and the width of the top concrete slab is $\mathrm{B}=1000 \mathrm{~mm}$. The thickness of the upper concrete panel is $t_{\mathrm{f}}=120 \mathrm{~mm}$. The height of the U-shaped steel beam is $\mathrm{h}=300$ $\mathrm{mm}$, and the total height of the T-shaped beam is $\mathrm{H}=400 \mathrm{~mm}$. The thickness of the U-shaped steel plate is $t_{\mathrm{f}}=4 \mathrm{~mm}$. The upper part of the inserted rebar is fixed with the upper main rebar $(\mathrm{d}=16 \mathrm{~mm})$, and the lower end hook is inserted into the U-shaped steel. The lower chord rebar of the rebar truss is welded with the upper flange of the U-shaped steel beam. In comparison with the traditional composite beams, the proposed construction method has no special requirements 
for the welding process and equipment, and the construction is convenient. Therefore, the assembled composite beam has promising application.

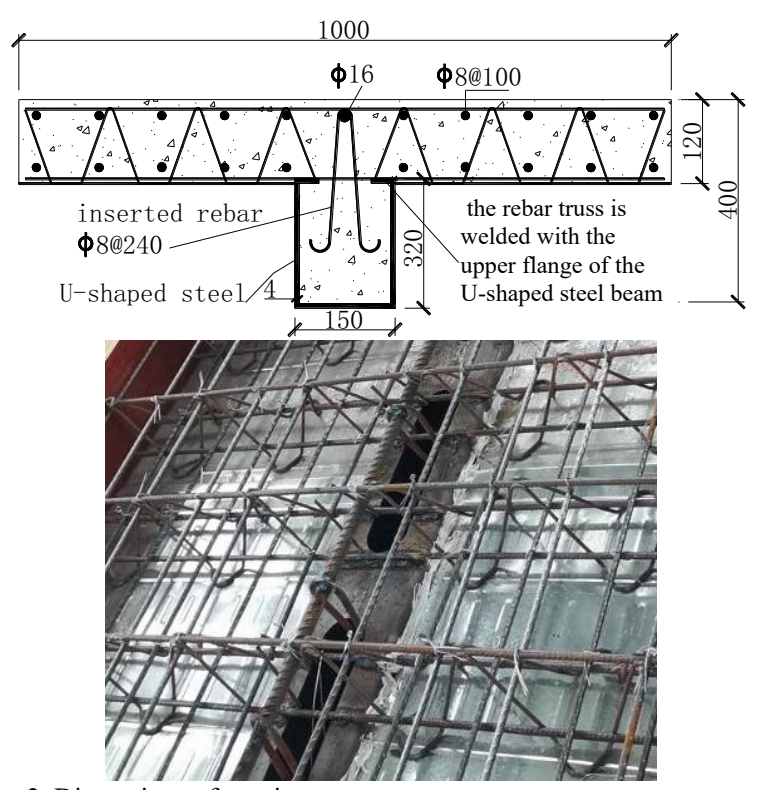

Fig. 2. Dimensions of specimens

In the test, two specimens are designed and labeled SCB1 and SCB2 to simulate positive and negative bending moments, respectively. The length of the specimen is 3000 $\mathrm{mm}$, the effective length of the load is $2800 \mathrm{~mm}$, the design strength grade of concrete is $\mathrm{C} 35$, and the measured standard cube strength is $38.6 \mathrm{MPa}$. Table 1 lists the mechanical properties of the steel plate and the reinforcing bar.

Table.1. Mechanical properties of steel

\begin{tabular}{c|c|c|c}
\hline Type & $\begin{array}{c}\text { Yield } \\
\text { strength } \\
f_{\mathrm{y}} / \mathbf{M P a}\end{array}$ & $\begin{array}{c}\text { Ultimate } \\
\text { strength } \\
f_{\mathrm{u}} / \mathbf{M P a}\end{array}$ & $\begin{array}{c}\text { Elastic } \\
\text { modulus } \\
E_{\mathrm{s}} / \mathbf{M P a}\end{array}$ \\
\hline $\begin{array}{c}\text { Rebar D=8 } \\
\mathrm{mm} \\
\text { Rebar D=16 } \\
\text { mm } \\
\begin{array}{c}\text { Steel plate } \\
\mathrm{t}=4 \mathrm{~mm}\end{array}\end{array}$ & 300 & 468 & $2.0 \times 10^{5}$ \\
\hline
\end{tabular}

\subsection{Layout of the loading device and test points}

Two-point symmetrical loading method is used. The loading device is shown in Figure 3(a). Preloading is implemented before the formal loading. After the device is normally operated, it is initially unloaded to 0 and then formally loaded. The loading is divided into three stages. The specimens are loaded according to the differential of $20 \mathrm{kN}$ before yielding. After yielding, the specimens are loaded on the basis of the load differential of $10 \mathrm{kN}$. After reaching the peak load, displacement control is implemented. The test is finished after the load is dropped to $85 \%$ of peak value. Each stage is loaded for $5 \mathrm{~min}$, and the test phenomenon is observed.

Figure 3(b) shows the displacement meter layout, where D4-D6 are used to measure deflection. D1 and D7 are used to measure the relative slip deformation of the Ushaped steel wall and the inner concrete (referred to as "wall concrete slip"). D2 and D8 measure the relative slip between the upper flange plate and the lower U-shaped steel (referred to as "plate steel beam slip"). D3 and D9 record the settlement of the supports. S1-S15 are the steel strain gauge. Figure 3(c) shows the layout of the strain gauge in the mid- span section. H1-H15 are the concrete strain gauge, and S1$\mathrm{S} 15$ are the steel strain gauge

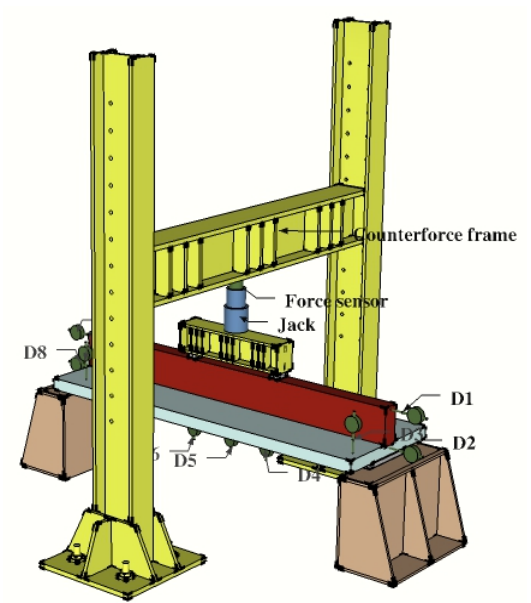

(a) Loading device

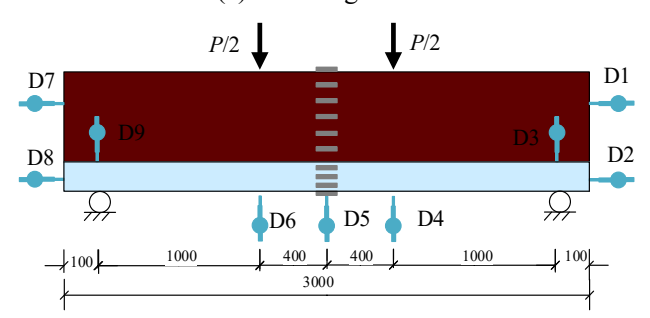

(b) Displacement meter

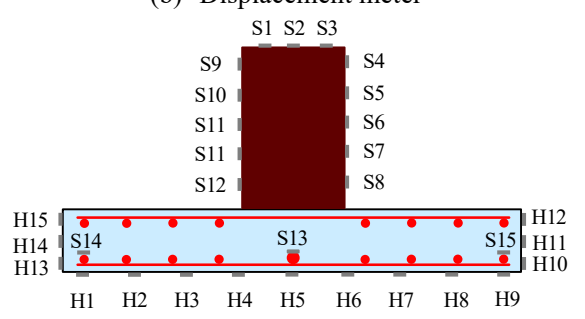

(c) Strain gauge of the mid-span section

Fig. 3. Test setup and measuring point distribution (SCB2)

\section{Result analysis and discussion}

\subsection{Failure process and form}

Specimen SCB1 simulating the positive bending moment is a typical ductile failure. The failure process is divided into four stages, namely, the initial stage, the crack initiation stage, the slip deformation development stage, and the failure stage. (1) In the initial stage, specimen SCB1 is in an elastic state. (2) In the crack initiation stage, when loading to $240 \mathrm{kN}$, the first crack appears in the flange plate concrete and penetrates at $520 \mathrm{kN}$. (3) In the slip deformation development stage, when the load reaches $600 \mathrm{kN}$, the slip deformation development accelerates. (4) In the failure stage, the load peaks to $680 \mathrm{kN}$ and remains stable for a long time. The concrete at the loading point of the flange plate is crushed and forms a straight joint. The width of the main crack is about $10 \mathrm{~mm}$, and the failure pattern is shown in Figure 4.

Brittle failure occurs in specimen SCB2 simulating negative bending moment. The failure process is as follows. (1) At the initial stage, specimen SCB2 is in an elastic state. (2) In the crack development stage, specimen SCB2 cracks earlier, and the flange plate cracks when loading to $120 \mathrm{kN}$, which extends to the top of the plate at $160 \mathrm{kN}$. The Ushaped steel is initially completely pressed and then partially tensioned. (3) Last is the failure stage. The load peaks at 750 
$\mathrm{kN}$, convex buckling occurs, and the bearing capacity decreases rapidly. Figure 5 shows the failure form of SCB2.
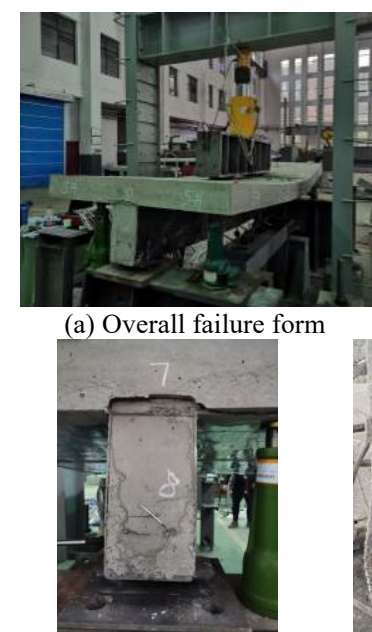

(c) Flange steel interface

Fig. 4. Deformation of inserted bars and lower chords

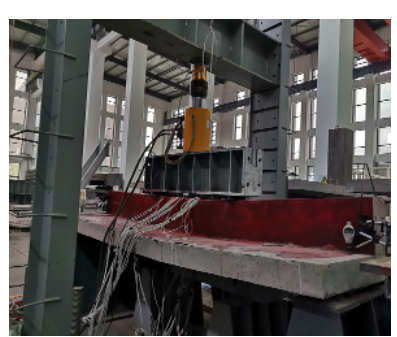

(a) Overall failure form

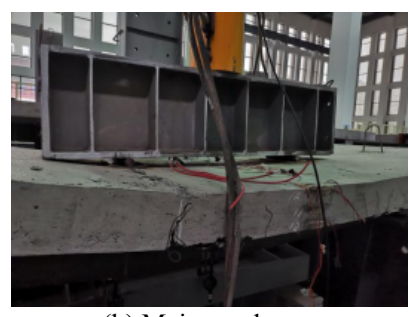

(b) Main crack

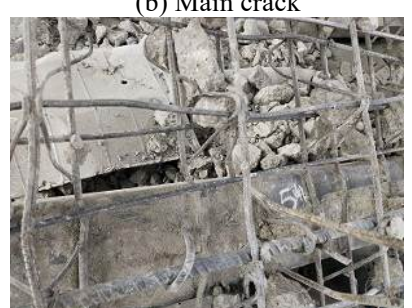

Deformation of lower chords

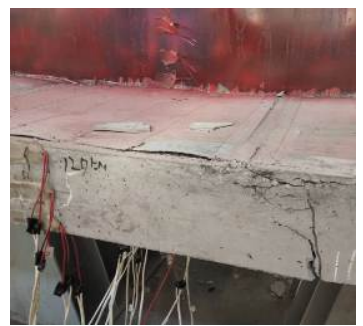

(b) Main crack

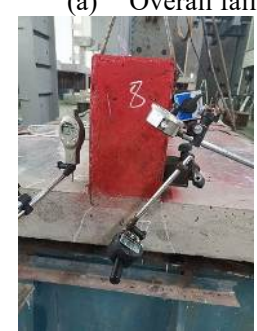

(c) Flange steel interface

Fig. 5. Failure mode of specimen SCB2

Given the difference in location and function of steel, the failure modes of specimens SCB1 and SCB2 are slightly different. (1) The main crack of specimen SCB1 is at the loading point, whereas that of specimen SCB2 is near the middle span, because the vertical load of SCB1 acts directly on the concrete and forms concentrated stress at the loading point. The flange load of specimen SCB2 is transferred from the steel beam (the U-shaped steel and inner concrete are referred to as "steel beam"), and the force is more uniform, thereby making the crack location different from that of SCB1. (2) The concrete of SCB1 flange plate is crushed, and the cracks penetrate. Steel and flange plates are obviously dislocated (the measured value of the slip at two ends is up to $19.52 \mathrm{~mm}$ ), and specimen SCB2 is destroyed by the convex buckling of the steel. No obvious relative slip deformation is observed between the steel and the flange plate, which results from the uncoordinated deformation of the steel plate and the flange plate of SCB1 under tension and pressure. The restraint effect of the U-shaped steel on the concrete at the flange plate is weakened. The concrete at the loading point is crushed, forming a through joint. After specimen SCB2 is cracked, the steel beam bears the most bending moment, and the upper pressure is larger. Convex buckling occurs at the two loading points and the mid-span section steel. The slip deformation is not fully developed due to the brittle failure of the specimen.

\subsection{Load-deflection curve and secant stiffness}

Figure 6 shows the load-mid-span deflection curve of the two specimens. The load and mid-span deflections of each characteristic point are shown in Table 2, where $\Delta_{\text {cr }}$ is the deflection of the first batch of crack; $P_{\text {cr }}$ and $M_{\text {cr }}$ are the corresponding load and bending moment, respectively; and $\Delta_{\mathrm{y}}$ represents yield deflection, which is calculated using equivalent energy method. $P_{\mathrm{y}}$ and $M_{\mathrm{y}}$ are the yield load and bending moment, respectively. $\Delta_{\mathrm{p}}, P_{\mathrm{p}}$, and $M_{\mathrm{p}}$ are the peak deflection, load, and bending moment, respectively. $\Delta_{\mathrm{u}}$ is the ultimate deflection, which is the deflection as the load decreases to $85 \% P_{\mathrm{p}}$. Specimen $\mathrm{SCB} 1$ has excellent deformation performance, and the load is still higher than $85 \% P_{\mathrm{p}}$ after loading. The test ends because of the distribution beam and the specimen contact. For comparison, as the load drops to $90 \% P_{\mathrm{p}}$, the deflection $\Delta_{\text {un }}$ is the nominal limit deflection; $\mu=\Delta_{\mathrm{u}} / \Delta_{\mathrm{y}}$ is the ductility factor; and $\mu_{\mathrm{n}}=\Delta_{\mathrm{un}} / \Delta_{\mathrm{y}}$ is the nominal ductility factor.

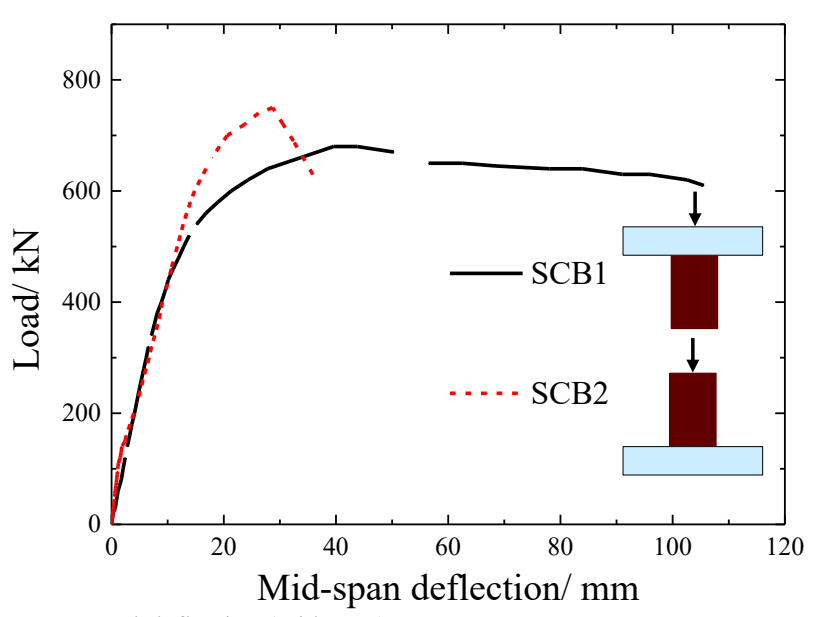

Fig. 6. Load-deflection (mid-span) curves

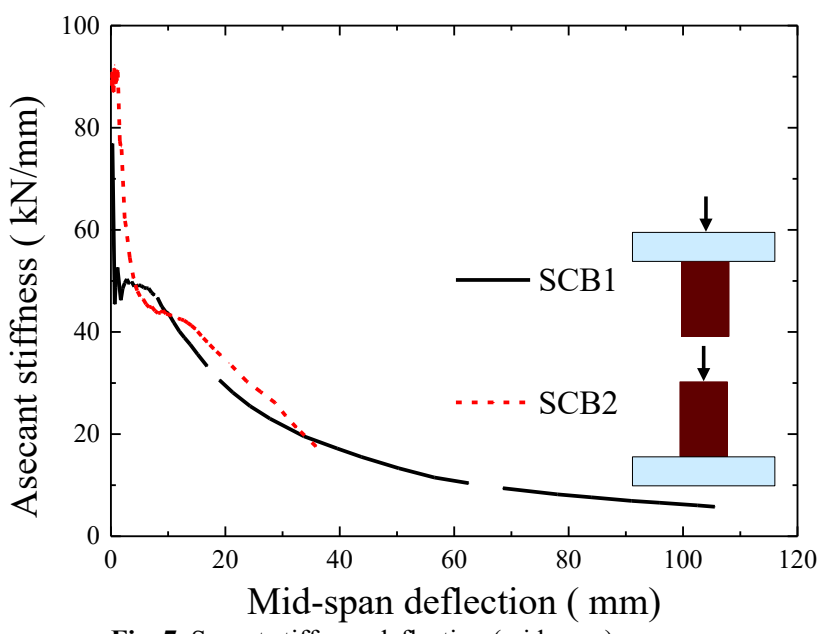

Fig. 7. Secant stiffness-deflection (mid-span) curves

Figure 7 shows the deflection-secant stiffness curve of the specimen. Table 3 compares the secant stiffness of the 
characteristic points (referred to as "stiffness"). $K_{\mathrm{cr}}, K_{\mathrm{y}}, K_{\mathrm{p}}$ and $K_{\text {un }}$ denotes the cracking, yield, peak, and nominal ultimate stiffness, respectively.

As shown from the comparison in Figures 6 and 7 and Tables 2 and 3, the bearing capacity and the initial stiffness of SCB1 are relatively low, and a long development process is observed from the yield to the limit state. The nominal ductility coefficient is as high as 5.34, showing strong deformation capacity. Combined with Figure $7(\mathrm{~d})$, the connection between the lower chord and the steel weld is not broken, and the same rebar bends obviously, which restrict the development of slip deformation during loading. The proposed novel composite beam structure is thus reasonable and can contribute to the cooperation of flange plate and steel beam. Moreover, it has good integrality and can be widely applied to practical engineering. SCB2 has higher load capacity and initial stiffness, but the peak load decreases rapidly, whereas the stiffness degrades rapidly. The nominal ductility coefficient of the former is only $33.7 \%$. The buckling of steel subjected to negative bending moment is still the main problem of the novel composite beam $[22,23]$.

Table 2. Characteristic load and deflection of the specimens

\begin{tabular}{|c|c|c|c|c|c|c|c|c|c|c|c|}
\hline Specimen & $\begin{array}{c}\Delta_{\mathrm{cr}} \\
(\mathrm{mm})\end{array}$ & $\begin{array}{c}P \\
(\mathrm{kN})\end{array}$ & $\begin{array}{c}M_{\mathrm{cr}} \\
(\mathrm{kN} \cdot \mathrm{m})\end{array}$ & $\begin{array}{c}\Delta_{\mathrm{y}} \\
(\mathrm{mm})\end{array}$ & $\begin{array}{c}P_{\mathrm{y}} \\
(\mathrm{kN})\end{array}$ & $\begin{array}{c}M_{\mathrm{y}} \\
(\mathrm{kN} \cdot \mathrm{m})\end{array}$ & $\begin{array}{c}\Delta_{\mathrm{P}} \\
(\mathrm{mm})\end{array}$ & $\begin{array}{c}P_{\mathrm{P}} \\
(\mathrm{kN})\end{array}$ & $\begin{array}{c}M_{\mathrm{P}} \\
(\mathrm{kN} \cdot \mathrm{m})\end{array}$ & $\Delta_{\mathrm{u}}\left(\Delta_{\mathrm{un}}\right)$ & $\mu\left(\mu_{n}\right)$ \\
\hline SCB1 & 4.88 & 240 & 120 & 19.67 & 586.0 & 293.0 & 39.57 & 680 & 340.0 & $(105.0)$ & $(5.34)$ \\
\hline SCB2 & 1.55 & 120 & 60 & 18.51 & 668.5 & 334.3 & 28.71 & 750 & 375.0 & $35.43(33.27)$ & $1.91(1.80)$ \\
\hline
\end{tabular}

Note: Data in brackets are nominal limit displacement and nominal ductility factor.

Table 3. Secant stiffness of the specimens

\begin{tabular}{c|c|c|c|c|c|c|c}
\hline Specimen & $K_{\text {cr }}(\mathrm{kN} / \mathrm{m})$ & $K_{\mathrm{y}}(\mathrm{kN} / \mathrm{m})$ & $K_{\mathrm{p}}(\mathrm{kN} / \mathrm{m})$ & $K_{\text {un }}(\mathrm{kN} / \mathrm{m})$ & $K_{\mathrm{y}} / K_{\text {cr }}$ & $K_{\mathrm{p}} / K_{\text {cr }}$ & $K_{\text {un }} / K_{\text {cr }}$ \\
\hline SCB1 & 49.18 & 29.79 & 17.18 & 5.83 & 0.61 & 0.35 & 0.12 \\
SCB2 & 77.42 & 36.12 & 26.12 & 20.29 & 0.47 & 0.34 & 0.26 \\
\hline
\end{tabular}

\subsection{Load-mid-span strain curve}

Figure 8 shows the tensile strain relation curve at the bottom of the load-mid-span section, where the strain data of $\mathrm{S} 2$ is used for SCB1, and the strain data of the measured point S13 is used for SCB2. The U-shaped encased steel concrete composite beam is composed of the flange plate and the steel beam, the flexural rigidity of which influence the strain distribution of the section. Internal force redistribution occurs after the SCB2 flange plate cracks, and the tensile stress of the steel bar increases suddenly. The flange plate is located in the tensile area; thus, the bending stiffness degrades rapidly, and the ratio of the bending moment is reduced. Therefore, the tensile strain is less sensitive to load change, and the strain increases slowly. After yielding, the bending moment of the flange plate is released, and the strain of S2 decreases (the load is $620 \mathrm{kN}$ ).

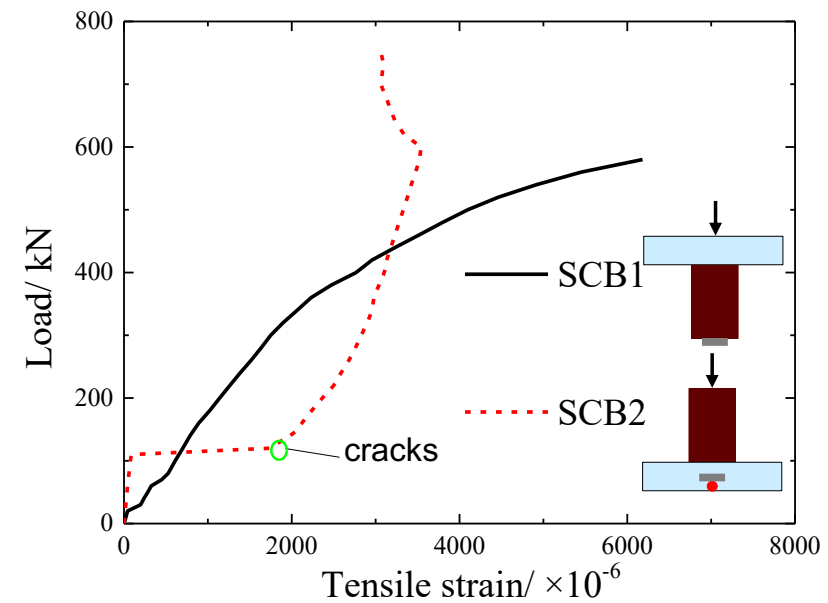

Fig. 8. Load-tensile strain relation curveat the bottom of the load-midspan section

\subsection{Section strain distribution of compression area}

Figure 9 shows the strain distribution along the height of the mid-span section. The strain distribution of specimen SCB1 does not conform to the assumption of the plane section. The strain in the middle and lower parts of the flange is smaller.
The reason for the phenomenon is that the U-shaped steel is embedded at $20 \mathrm{~mm}$ of the flange, and the section size at the interface changes. The flange plate shares the compressive stress of the steel, resulting in small strain and discontinuous strain distribution. Specimen SCB2 also has similar characteristics before cracking. On the basis of the local strain distribution, the strain of the steel beam is linearly distributed before SCB1 yielding and is nonlinearly distributed after yielding. The strain of SCB2 is linearly distributed before yielding and after cracking and is nonlinearly distributed after cracking.

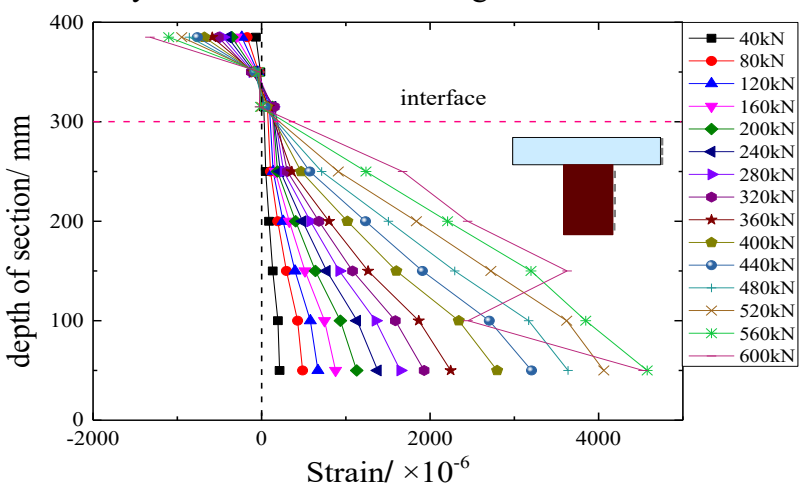

(a) Entire process of SCB1

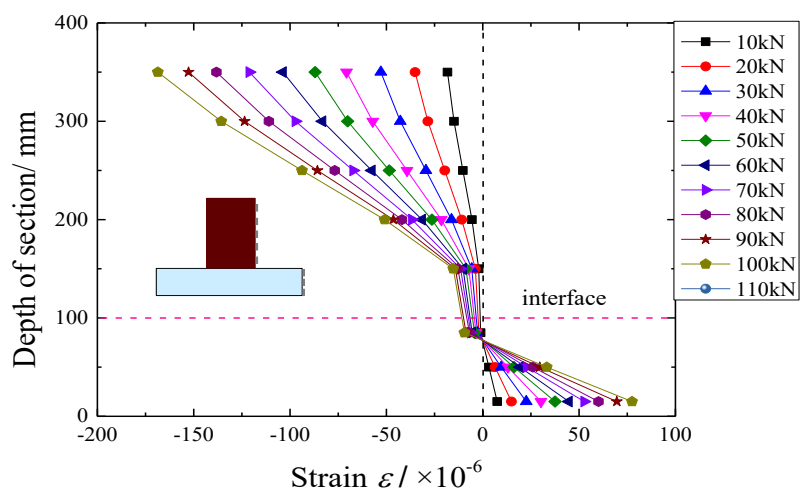

(b) Before cracking of SCB2 


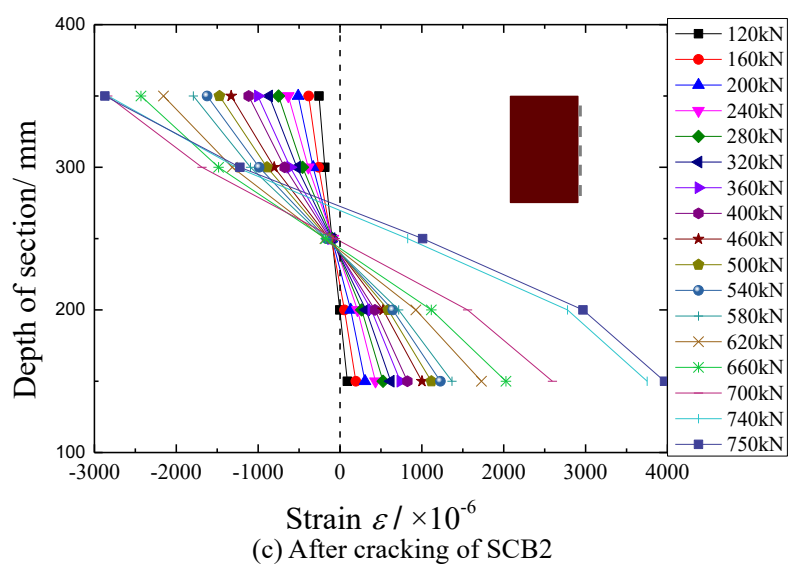

Fig. 9. Strain distribution of the mid-span section

\subsection{Global performance analysis}

Under positive and negative bending moments, the composite beam shows different stiffness and strain distribution laws, which influence the deformation characteristics and the global performance. The global performance can be reflected by strain distribution, slip deformation, and deflection distribution.

Figures 10 and 11 show the strain distribution of the mid-span section flange concrete ( $\mathrm{H} 1-\mathrm{H} 9$ strain data) and longitudinal strain (S13-S15 strain data). The strain in the middle part of SCB1 flange plate (including concrete and longitudinal rebar) is greater, and the strain at the edge is small, showing obvious shear lag. The lag effect is intensified with loading. The concrete and longitudinal rebar in the middle of the flange plate has a small strain before cracking. The concrete shows an M-shaped strain distribution. After cracking, the strain in the middle part (longitudinal rebar) is larger because the large rigidity of the steel beam has a shear lag effect on the flange plate. Stress concentration occurs at the contact point between the ends and flange plates (the length direction from the mid-span is $1400 \mathrm{~mm}$ ), thereby influencing the strain distribution in the mid-span section. The effect before cracking cannot be ignored. Under the combined influence of the above two factors, the strain in the middle part is small, and the concrete strain shows an M-shaped distribution. However, the shear lag effect increases after cracking, whereas the support effect decreases. Therefore, the strain in the middle part is the maximum.

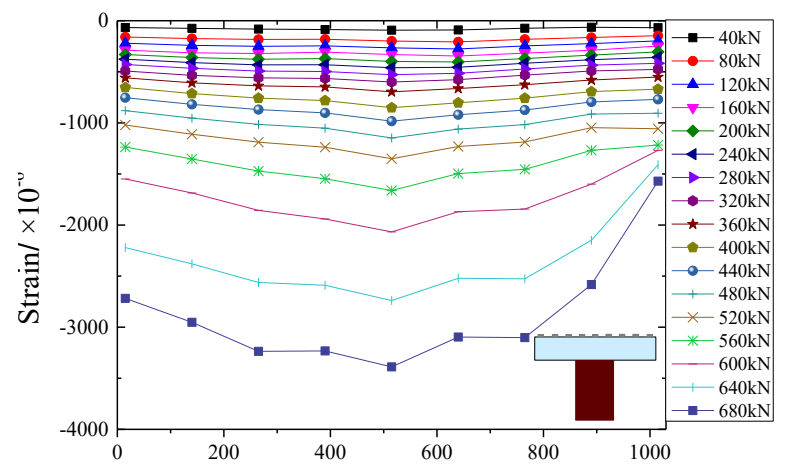

Distance from edge of beam/ $\mathrm{mm}$

(a) Compression strain distribution of SCB1 flange plate

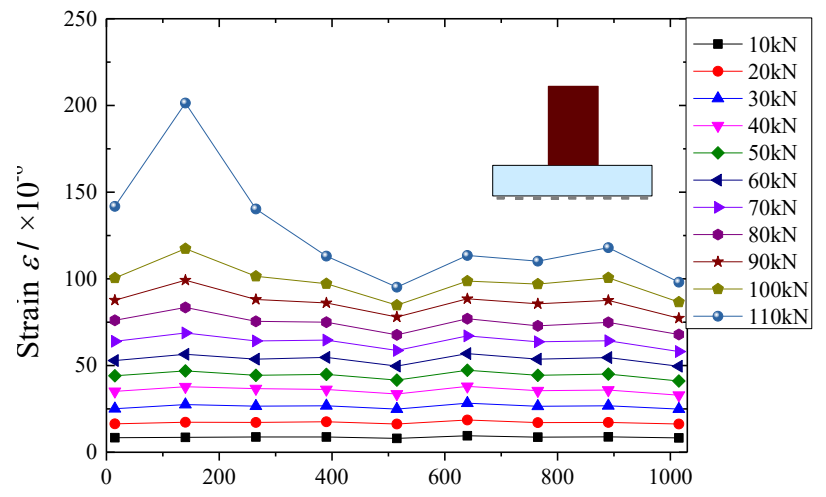

Distance from edge of beam/ $\mathrm{mm}$

(b)Tensile strain distribution of SCB2 flange plate (before cracking) Fig. 10. Sectional strain of the concrete at the flange in transverse direction

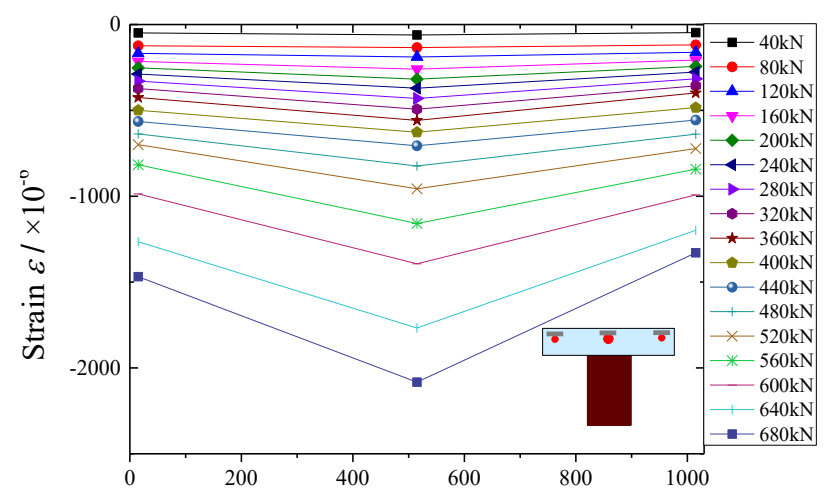

Distance from edge of beam $/ \mathrm{mm}$

(a) Compression strain distribution of SCB1 flange plate

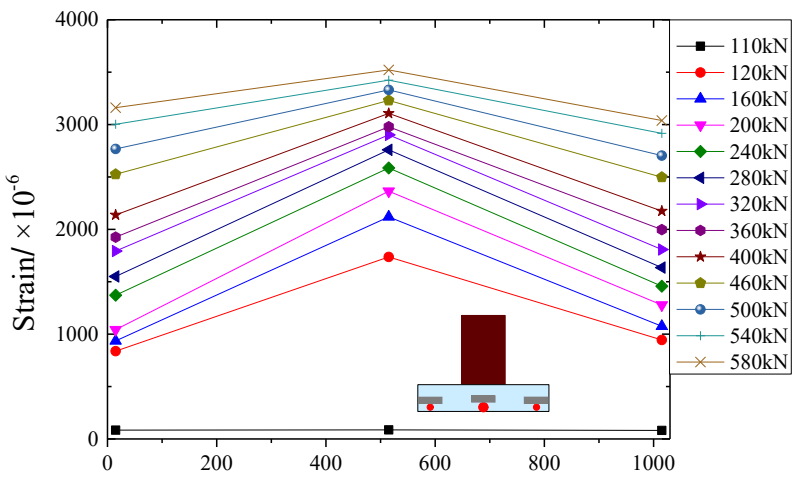

Distance from edge of beam $/ \mathrm{mm}$

(b) Tensile strain distribution of SCB2 flange plate

Fig. 11. Sectional strain of the rebar at the flange in transverse direction

\section{Conclusion}

To improve the mechanical properties of the existing Ushaped steel reinforced concrete composite beams, a novel concrete composite beams stiffened by fabricated rebar truss with U-shaped steel girders was developed, and its mechanical performance under positive and negative bending moment was compared. The following conclusions could be drawn.

(1) Specimen SCB1 under positive bending moment has low bearing capacity and initial stiffness, and the interface slip deformation is fully developed. The specimen is eventually destroyed due to the crush of the flange concrete, which is ductile failure. Moreover, it has strong deformation capacity. The starter rebars between the interface connection and the lower chord tendons of the 
rebar truss are obviously yielded, which can restrict the relative slippage of the flange plate and the steel beam. The proposed composite beam is proven to have reliable structure and simple construction method. Moreover, it has no special requirements for welding technology and equipment and can be applied to the fabricated structural industry.

(2) Specimen SCB2 under negative bending moment has large initial stiffness and high bearing capacity, but its stiffness decreases rapidly after cracking. The failure mode of the specimen is brittle failure due to the buckling of the steel, and its deformation performance is also poor, indicating that the main problem of the proposed composite beam is the buckling of steel under negative bending.

(3) The strain distribution of the two specimens (midspan section) is not consistent with the assumption of the plane section. However, the strain of the steel beam is linearly distributed before yielding and nonlinearly distributed after yielding. The depth of the compressive zone decreases after cracking, but the depth of SCB1 compressive zone is stable before the peak stage and after cracking. In comparison, the depth of the compressive zone of SCB2 decreases again after yielding.

(4) After cracking, the longitudinal tensile strain of the flange plate of SCB2 increases abruptly, and the increase then slows down. After yielding, the strain even decreases. The compressive strain of negative bending moment is more sensitive to load change. Under the same load, the strain at the top of SCB2 is significantly higher than that of SCB1 (concrete strain).

This study proposed a novel concrete composite beams stiffened by fabricated rebar truss with U-shaped steel girders. This composite beam has reliable and simple configuration, has no special requirements for welding technology and equipment, and can be applied to the practical fabricated structural industry. The test results provide reference for the popularization and application of fabricated composite beams. Future studies can consider strengthening measures for U-shaped beams at the section of negative bending moment to avoid buckling of steel under compression.

\section{Acknowledgements}

This work was supported by the National Natural Science Foundation of China (51778219), the Natural Science Foundation of Hunan Province (2020JJ5018; 2020JJ5020; 2018JJ2020), and the Scientific Research Project of Education Department of Hunan Province (19B099).

This is an Open Access article distributed under the terms of the Creative Commons Attribution License

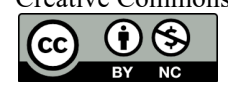

\section{References}

1. Galambos, T. V., "Recent research and design developments in steel and composite steel-concrete in USA". Journal of Constructional Steel Research, 55(2), 2000, pp.289-303.

2. Lapko, A., Bara, S. B., "Experimental and numerical analysis of flexural composite beams with partial use of high strength high performance concrete". Journal of Civil Engineering and Management, 11(2), 2005, pp.115-120.

3. Sallam, H. E. M., Badawy, A. A. M., Saba, A. M., "Flexural behavior of strengthened steel-concrete composite beams by various plating methods". Journal of Constructional Steel Research, 66(2), 2010, pp.1081-1087.

4. Nie, J. G., "Principles and Examples of steel-concrete composite structures". Beijing: China Science Press, 2003, pp.1-24.

5. Zhou, X. H., Zhao, Y., Liu, J. P., "Bending experiment on a novel configuration of cold-formed U-shaped steel-concrete composite beams". Engineering Structures, 180, 2019, pp.124-133.

6. Guo, X., "Research on flexural behavior of a noval cold-formed $U$ shaped steel-concrete composite beam". Master thesis of Chongqing University, China, 2018, pp.22-27.

7. Zhang, Y. L., Hou, Z., Li, Y., Wang, Y., "Torsional behaviour of curved composite beams in construction stage and diaphragm effects". Journal of Constructional Steel Research, 108(1), 2015, pp. $1-10$.

8. Ban, H., Tan, E. L., Uy, B., "Strength of multi-span composite beams subjected to combined flexure and torsion". Journal of Constructional Steel Research, 113(2), 2015, pp.1-12.

9. Bidabad, B. S., Naeini, H. M., Tehrani, M. S., Barghikar, H., "Experimental and numerical study of bowing defects in cold rollformed U-channel sections". Journal of Constructional Steel Research. 118(2), 2016, pp.243-253.

10. Bousselham, A., Chaallal, O., "Experimental investigations on the influence of size on the performance of RC T-beams retrofitted in shear with CFRP fabrics". Engineering Structures, 56(1), 2013, pp.1070-1090.

11. Kotsovou, G. M., Cotsovos, D. M., "Shear failure criterion for RC T-beams". Engineering Structures, 160(4), 2018, pp.44-55.

12. Liu, Y., Guo, L. H., Qu, B., Zhang, S. M., "Experimental investigation on the flexural behavior of steel-concrete composite beams with U-shaped steel girders and angle connectors". Engineering Structures, 131(2), 2017, pp.492-502
13. Uy, B., Bradford, M. A., "Profiled Composite Beam and Slab Systems". Building for the 21th Century, 1(1), 1995, pp.463-468.

14. Ariel, H., "Tests of composite beams with cold-formed sections". Journal of Constructional Steel Research, 54(4), 2000, pp.245-264.

15. Patel, V. I., Uy, B., Pathirana, S. W., Wood, S., Singh, M., "Finite element analysis of demountable steel-concrete composite beams under static loading". Advanced Steel Construction, 14(3), 2018, pp.392-411.

16. Xiao, H., Li, A. Q., Du, D., "Experimental Study on ultimate flexural capacity of steel encased concrete composite beams". Journal of Southeast University, 21(2), 2005, pp.191-196.

17. Chen, L. H., Li, A. Q., Lou, Y., Li, P. B., "Ultimate negative bending-moment capacity of outer plated steel-concrete continuous composite beams". Journal of Southeast University, 25(1), 2009, pp.89-93.

18. Cao, L. L., Shi, Q. Y., Wang, Z., "Bending performances of highstrength steel-encased composite beams". Journal of Southwest Jiaotong University, 49(1), 2014, pp.72-78.

19. Zhang, Z. C., Fan, X. H., Yang, F., "Experimental research on section design and internal Force redistribution of inverted Ushaped high-strength encased steel and high-strength concrete continuous composite beam". Building Structure, 49(6), 2019, pp.55-60.

20. Yan, Q. W., Zhang, Z., “Analysis of normal section bending bearing capacity of inverted U-Shaped steel-encased concrete composite beam". Journal of Civil and Environmental Engineering, 42(6), 2020, pp.1-14

21. Keo, P., Lepourry, C., Somja, H., "Behavior of a new shear connector for U-shaped steel-concrete hybrid beams". Journal of Constructional Steel Research, 145(3), 2018, pp.153-166.

22. Liu, J. P., Zhao, Y., Chen, Y. F., Xu, S. Q., "Flexural behavior of rebar truss stiffened cold-formed U-shaped steel-concrete composite beams". Journal of Constructional Steel Research. 150(3), 2018, pp.175-185.

23. Liu, J., Zhao, Y., Yang, Y., Chen, Y. F., "Bending capacity and elastic stiffness for a novel configuration of cold-formed U-shaped steel and concrete composite beams". Journal of Constructional Steel Research, 145(10), 2019, 04019106.

24. Zhao, Y., Zhou, X. H., Yang, Y. L., Liu, J. P., "Torsional effects of a novel rebar stiffened cold-formed U-shaped steel-concrete composite beam system". Engineering Structures, 2019,109920. 
25. Kim, S. B., Lee, E. T., Kim, J. R., Kim, S. S., "Experimental study on bending behavior and seismic performance of hybrid composite beam with new shape". International Journal of Steel Structures, 16(2), 2016, pp.477-88.

26. Kemp, A. R., "Inelastic local and lateral buckling in design codes". Journal of Structural Engineering, 122(4), ASCE, 1996, pp.374382 .
27. Tong, L. W., Liu, Y., Sun, B., "Experimental investigation on mechanical behavior of steel-concrete composite beams under negative bending". Journal of Building Structures, 35(10), 2014, pp.1-9.

28. Yang, H. L., Zheng, Y. M., Shi, X., "Experimental investigation effect of partially-filled concrete on mechanical behavior of narrow-width steel box concrete". Journal of Building Structures, 40(11),

pp.131-139. 